\title{
Understanding health behaviour in pregnancy and infant feeding intentions in low-income women from the UK through qualitative visual methods and application to the COM-B (Capability, Opportunity, Motivation-Behaviour) model
}

\author{
Aimee Grant ${ }^{*}$ (D), Melanie Morgan ${ }^{1}$, Dawn Mannay ${ }^{2}$ and Dunla Gallagher ${ }^{3}$
}

\begin{abstract}
Background: Health behaviours during pregnancy and the early years of life have been proven to affect long term health, resulting in investment in interventions. However, interventions often have low levels of completion and limited effectiveness. Consequently, it is increasingly important for interventions to be based on both behaviour change theories and techniques, and the accounts of pregnant women. This study engaged with pregnant women from deprived communities, to understand their subjective experiences of health in pregnancy.

Methods: The study adopted a women-centred ethos and recruited a purposive sample of ten pregnant women, who lived in deprived areas and were on low incomes. Participants engaged with three creative techniques of visual data production (timelines, collaging and dyad sandboxing), followed by elicitation interviews. One participant only engaged in the initial activity and interview, resulting in a total of 28 elicitation interviews. This in-depth qualitative approach was designed to enable a nuanced account of the participants' thoughts, everyday experiences and social relationships. Data were deductively coded for alcohol, smoking and infant feeding and then mapped to the COM-B model (Capability, Opportunity, Motivation - Behaviour).

Results: Five participants had experience of smoking during pregnancy, four had consumed alcohol during pregnancy, and all participants, except one who had exclusively formula fed her child, disclosed a range of infant feeding experiences and intentions for their current pregnancies. Considerable variation was identified between the drivers of behaviour around infant feeding and that related to abstinence from tobacco and alcohol during pregnancy. Overall, knowledge and confidence (psychological capability), the role of partners (social opportunity) and support from services to overcome physical challenges (environmental opportunity) were reported to impact on (reflective) motivation, and thus women's behaviour. The role of the public in creating and reinforcing stigma (social opportunity) was also noted in relation to all three behaviours.

\footnotetext{
* Correspondence: GrantA2@cardiff.ac.uk

${ }^{1}$ Centre for Trials Research, Cardiff University Neuadd Meirionnydd, Heath

Park, Cardiff CF14 4YS, UK, Wales

Full list of author information is available at the end of the article
}

(c) The Author(s). 2019 Open Access This article is distributed under the terms of the Creative Commons Attribution 4.0 International License (http://creativecommons.org/licenses/by/4.0/), which permits unrestricted use, distribution, and reproduction in any medium, provided you give appropriate credit to the original author(s) and the source, provide a link to the Creative Commons license, and indicate if changes were made. The Creative Commons Public Domain Dedication waiver (http://creativecommons.org/publicdomain/zero/1.0/) applies to the data made available in this article, unless otherwise stated. 
(Continued from previous page)

Conclusions: When designing new interventions to improve maternal health behaviours it is important to consider the accounts of pregnant women. Acknowledging pregnant women's subjective experiences and the challenges they face in negotiating acceptable forms of motherhood, can contribute to informed policy and practice, which can engage rather than isolate potential user groups.

Keywords: Pregnancy, Antenatal, Smoking, Alcohol, Infant feeding, Breastfeeding, Qualitative, Visual methods, Creative methods, COM-B model,

\section{Background}

The negative impact of health behaviours during pregnancy, including smoking [1] and drinking alcohol [2], on outcomes in infancy and beyond has been clearly established. Within Western countries, this has resulted in guidance on maternal behaviours which should be avoided. For example, in the United Kingdom (UK), abstinence from smoking and medicinal nicotine containing products (such as Nicotine Replacement Therapy) is recommended throughout pregnancy [3]. In January 2016, UK guidance changed to recommend complete abstinence from alcohol during the pre-conception period and throughout pregnancy [4]. It should be noted this change to guidance has been contentious in public health circles, where a lack of robust epidemiological evidence is highlighted [5]. However, qualitative research with women in Australia, found that overall women accept the guidance to be abstinent in principle, even if they do not follow it themselves [6]. In regards to infant feeding, the UK National Health Service advocates World Health Organization guidance in relation to infant feeding, recommending exclusive breastfeeding for the first six months, and breastfeeding alongside the introduction of solid food until at least two years of age $[7,8]$.

In many Western countries, investment is being made in public health interventions intended to support women to meet this public health guidance. The majority of interventions focus on changing the behaviour of the individual woman. Arguably, this emphasis can assume the superiority of the foetus over the mothers' health [9], and neglect the social context of the health behaviour in women's lives [10]. Pregnant women have reported that interventions may be rushed, judgemental and didactic [11] and can reinforce the behaviour they seek to prevent through shaming participants [12].

Midwives involved in the delivery of these interventions have highlighted a lack of time, training and resources to facilitate these roles [13]. It is therefore unsurprising that many interventions targeted at women from the most deprived areas, or who engage in behaviours that are detrimental to healthy pregnancies, often have low uptake and high dropout [14]. However, even where interventions have engaged women, they have not necessarily delivered benefits in terms of health behaviours in pregnancy, such as reduced smoking [15]. The use of financial incentives has been found to be cost effective in relation to maternal smoking cessation $[16,17]$ and feasible to deliver in relation to infant feeding [18]. However, this approach is not currently accepted by policymakers [19], health professionals [20] or the public [21], so is unlikely to be widely adopted.

An alternative way to improve health behaviour in pregnancy and the early years may be to examine the social-environmental contexts of behaviours, in order to devise supportive interventions to enable health promotion at a societal level [22]. For example, a wide range of adaptations are recommended to create a society that is breastfeeding-friendly [23]. One approach to theorising behaviour in this way is the COM-B model [24]. The COM-B model proposes that 'Behaviour' can be understood as a result of Capability, Opportunity, and Motivation (see Table 1). These three factors interact to produce behaviour, and may explain the differences in pregnancy related health behaviour among socio-economic groups, who have different Capability and Opportunity to change behaviour, regardless of Motivation. Arguably, a lack of consideration of Capability, Opportunity and Motivation within an individuals' environment, limits the potential impact of interventions, as they do not address wide ranging influences on behaviour.

As many interventions targeted towards deprived women in pregnancy are either not possible to deliver at a sufficient dose, or are not effective, it is important to generate a solid understanding of the baseline behavioural system in pregnant women, ahead of attempting to design interventions. Service users' views have been incorporated into the COM-B model in a range of

Table 1 COM-B domains (based on Michie et al., 2014)

\begin{tabular}{lll}
\hline & Domain & Examples \\
\hline Capability & Physical & Skills, strength, stamina \\
& Psychological & Knowledge, confidence, memory \\
Opportunity & Social & Social norms, interpersonal influences \\
& Environmental & Resources, physical environment \\
Motivation & Automatic & Impulses, desires, addiction \\
& Reflective & Beliefs, intentions \\
\hline
\end{tabular}


studies including a survey of Australian women regarding diet in pregnancy [25], infant feeding [26] Aboriginal women in relation to smoking cessation [27], and $\mathrm{Ku}-$ waiti women in relation to oral care in pregnancy [28]. Furthermore, this research has been used to develop new interventions. For example, low income UK women were engaged in designing a new breastfeeding peer support intervention using the COM-B model [29] and this intervention was subsequently found to be acceptable to women and health professionals [30]. To date, however, a broader understanding of multiple health behaviours in pregnancy among low income women has not been applied to the COM-B model. This is of particular relevance in maternal health, as due to the time-critical nature of healthy pregnancy interventions, multiple public health interventions need to be offered as a matter of urgency [31]. These diverse interventions are often delivered by midwifery staff as part of usual maternity care pathways [13].

\section{Methods}

Our research was situated in an interpretivist paradigm as it was primarily interested in the subjective perspectives, meaning making and understandings of the participants. It aimed to: (i) use creative methods with pregnant women living in deprived areas on a low income in the UK to facilitate discussion of experiences and thoughts in relation to health behaviours and pregnancy; (ii) to map these findings to the COM-B Model; and (iii) to report this research in line with COREQ guidelines (Additional file 1) [32]. The research design was directly informed by a workshop with 12 women who had children aged under two years who attended a pre-existing mother and baby group in a deprived area of south Wales, UK. This form of consultation prior to conceptualising the research design sought to bridge the divide between academic research and practitioner and service user needs, and maximise the impact and influence of research study.

\section{Study design and sample}

The research aimed to centre and value the participants' subjective accounts, positioning them as 'experts by experience' [33]. This was important as women in low income areas are often marginalised and have little voice in the policies that impact their lives. The approach was interested in both current experiences and the ways in which these were impacted by participants' wider biographies. Additionally, the design moved away from the research led 'question and answer' format by introducing creative activities, which enabled participants to lead and direct the discussions around the data that they produced [34-36]..
To ensure that the research was seen as impartial, and not related to the health service, a purposive sample of participants were recruited externally from the health service. We recruited participants from the research team's social networks using face-to-face discussions with family, friends and acquaintances $(n=$ 2 ), flyers and personal recommendations from staff at well attended mother and baby groups $(n=6)$, and through local social media groups aimed at mothers $(\mathrm{n}=2)$. We also attempted to recruit participants using flyers in local communities that were part of the Flying Start programme and where the researchers had a local connection, but did not recruit any participants using this approach. Due to this multi-faceted approach it is not possible to give a precise number of those who chose not to engage in the study. In recruitment materials, the study was titled "Health and Wellbeing in Pregnancy", to reduce the stigma associated with risky health behaviours in pregnancy. The recruitment materials emphasised that we wanted women to tell their story through the use of creative tasks and interviews taking around four hours of their time, and that we would be able to thank them for their time through the use of shopping vouchers ( $£ 25$ per phase, up to a maximum of $£ 50)$. We recruited 10 women who were less than 30 weeks pregnant at the time of their first interview. All women were pregnant, resident in areas of the highest quintile of deprivation according to the Welsh Index of Multiple Deprivation [37], and were claiming means tested (welfare) benefits, as per the study's inclusion criteria. All participants were involved in phase one, nine of the original 10 participants took part in the second data collection period. The 10th participant was lost to follow up.

\section{Researchers and positionality}

Three female researchers were involved in the fieldwork. Melanie a post-doctoral research assistant who has two adult children, Dawn, a senior lecturer who has adult children and young grandchildren and Dunla a research assistant and doctoral student who was pregnant during data production. Aimee, an experienced qualitative researcher, who does not have children, provided weekly support to Melanie and Dunla. Dawn provided specialist methodological support on a monthly basis. Researcher positionality [38] and personality [39] impact on the data produced. For example, one participant who did not disclose smoking during pregnancy to Dunla, subsequently disclosed this to Dawn. This illustrates the ways in which the commonality of motherhood was further complicated by other characteristics, such as age, class, biography, and national and local identity. All researchers kept field diaries in order to aid reflexivity. 
Ethics, consent, permissions and permission to publish All participants were asked to provide written informed consent to take part in the research. Participants chose whether they gave consent for their interviews to be audio recorded and/or for anonymised quotations to be used in reporting findings; all participants agreed to both of these voluntary permissions. All participants were allocated a pseudonym. The research was granted ethical approval by Cardiff University School of Medicine Research Ethics Committee.

\section{Data production}

Data were produced through a pre-interview task followed by an elicitation interview, and this process was repeated three times using different creative tasks (see Fig. 1). In the instructions that accompanied the pre-interview packs, which were sent by post, and in all telephone/text message correspondence with the research team participants were reminded of the study's aim and funding and given a choice of how to engage with the task, and they could select which information to include and exclude. The elicitation interviews were conducted during two phases, with interview one occurring in phase one, and interviews two and three occurring on the same day in phase two. Phases one and two were, approximately one month apart at the convenience of the interviewee. All data were produced between March and August 2016. All interviews occurred in participants' homes. Non-participants, including partners, children and occasionally other family members, were sometimes present.

During the first phase, participants were asked to create a timeline of their life prior to the interview [40], and were sent a resource pack including a timeline template, a range of alternative paper to use, and coloured stickers and pens to represent emotions [41]. Instructions asked participants to: "write a brief timeline of key events in your life". This method enabled the participants to reflect on their lives ahead of the interview, and to direct their life history interview through reference to their timeline, leading the direction and pace of the interview. The purpose of a life history interview was to situate each woman's experiences of being pregnant and of risky health behaviours in the context of their wider biographies. All 10 participants took part in this first phase of data production.

During phase two, participants undertook a further two interviews. Participants were sent a second pre-interview pack, which included (i) materials for producing a collage - a range of coloured papers, stickers and glue and (ii) a template which contained a picture of a pregnant woman's torso surrounded by thought bubbles. In these pre-tasks, participants were asked to consider: "how being pregnant impacts your everyday life". The option of a primarily visual or primarily written pre-task, enabled participants to select an activity which best suited their preferences. This pre-task was designed to encourage participants to focus on the lived experience of their current (and any previous) pregnancies.

Following the second elicitation interview, the researcher and participant engaged in a third creative activity, dyad sandboxing [42]. The researcher and participant each used a sand-tray and a range of figures to metaphorically describe: "what pregnancy is like on a day to day basis". The sandboxing activity enabled metaphoric communication through a range of $3 \mathrm{D}$ figures and objects to reflect further on the themes arising in interview two. This final elicitation interview took a dyad approach, involving the participant and researcher, for two reasons. Firstly, on a practical level, participants would be less likely to feel self-conscious in creating a sand-scene if the researcher was similarly occupied. Secondly, the shared nature of the activity both enabled a more equal encounter, and allowed conversations to develop around the experiences of both the researchers and the participants [39].

The researcher and participant generally sat separately and quietly spent around $10 \mathrm{~min}$ creating a sand-scene. This part of phase two was not audio recorded. When the sand-scene was complete, the researcher and

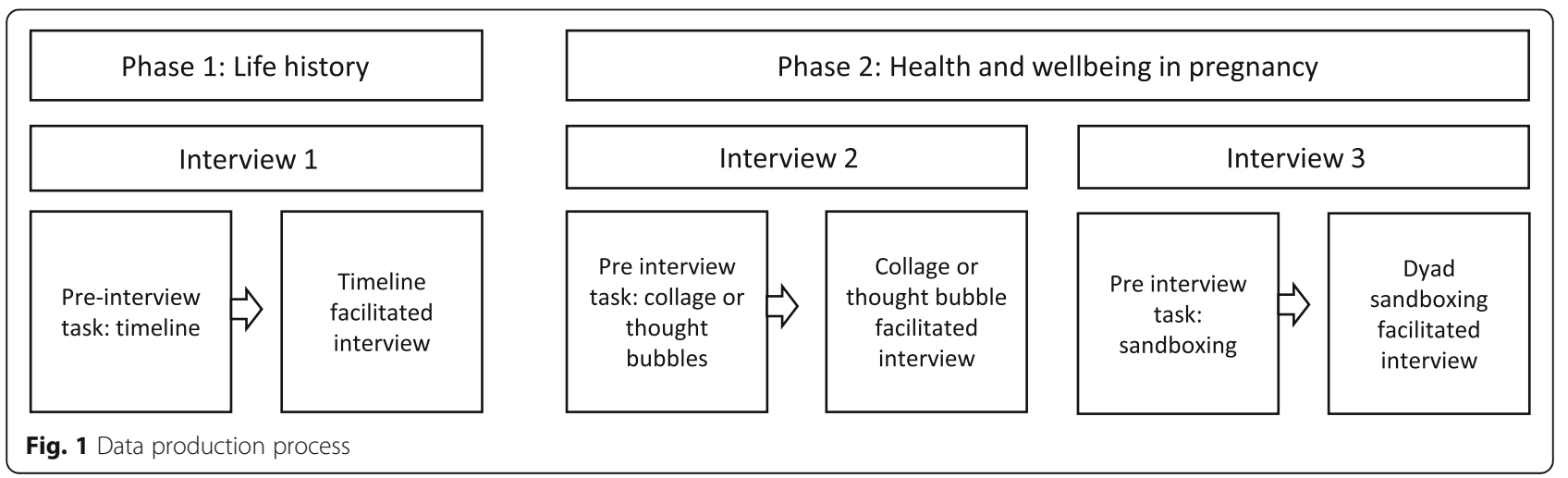


participant sat together for the third and final audio-recorded elicitation interview. First the participant described their experiences of pregnancy through their sand-scene, and then the researcher used their own sand-scene in the same way. Areas of similarity and difference were discussed. This joint engagement led to new conversations and further insights around health behaviours, which would not have arisen without the researchers openly sharing their own experiences of pregnancy.

Overall, participants responded well to requests to produce visual data. Only two of the 28 interviews were conducted without a participant created visual artefact (see Table 2). These two participants highlighted that the task was daunting, but further guidance and reassurance enabled them to produce visual data in both interviews within phase 2 . The use of multiple creative methods across the three interviews, each tailored to the specific focus of the interview, allowed participants to reflect on their experiences. Participants found it interesting to reflect on their lives, and although some discussed distressing memories, they still found the process productive. This suggests that the study's design worked well to both engage participants and share their experiences in a supportive environment.

\section{Data analysis}

Interviews were audio recorded and fully transcribed. An error occurred with a dictaphone in one interview, and 40 minutes did not record. This was realised immediately following the interview, and the researcher used the participant's comprehensive timeline to help jog her memory and write detailed fieldnotes. The interview transcripts ranged from 5000 to
18,000 words, and included large sections of monologue from participants. Transcripts were imported into NVivo 11 for thematic analysis based upon themes that had been identified by the research questions and others which became apparent during data production (deductive), and those that became apparent during coding (inductive). Participant created visual materials were viewed alongside interview transcripts, but were largely treated as elicitation tools rather than data to be separately analysed. Melanie coded all data, and met with Aimee for regular analysis workshops. Codes relating to three pre-identified primary health behaviours - smoking during pregnancy, drinking alcohol during pregnancy and infant feeding - were then second coded throughout the entire data set by Aimee. Areas of differential coding were discussed and resolved.

Data from the codes were deductively mapped to the COM-B model [43] by one researcher Aimee. Each data extract from the codes relating to smoking, drinking alcohol or infant feeding, was assigned to one or more of the six COM-B domains within a Microsoft Word 2013 document. Following extraction, discussion occurred with the remaining members of the research team and a colleague familiar with the COM-B model to ensure appropriate coding [44]. Participants were not invited to provide feedback on the analysis, as our initial research design consultation with mothers suggested that this would be burdensome in a study which already required four hours of participants' time. We focused on achieving a high level of 'information power' within our sample to adequately address the research questions, as opposed to the analysis aiming to achieve 'saturation', a contested concept within qualitative research, due to the pre-determined sample size [45]. Alongside the primary

Table 2 Data produced and engagement with participatory visual method tasks

\begin{tabular}{|c|c|c|c|c|c|c|c|}
\hline \multirow[t]{2}{*}{ Participant } & \multicolumn{2}{|l|}{ Phase 1} & \multicolumn{4}{|l|}{ Phase 2} & \multirow{2}{*}{$\begin{array}{l}\text { Total } \\
\text { word } \\
\text { count }\end{array}$} \\
\hline & $\begin{array}{l}\text { 1st Pre-Interview } \\
\text { Timeline Task }\end{array}$ & $\begin{array}{l}\text { Phase } 1 \\
\text { Word count }\end{array}$ & $\begin{array}{l}\text { 2nd Pre-Interview Thought } \\
\text { Bubbles Task }\end{array}$ & $\begin{array}{l}\text { 2nd Pre-Interview } \\
\text { Collage Task }\end{array}$ & $\begin{array}{l}\text { 3rd Pre-interview } \\
\text { Sandboxing task }\end{array}$ & $\begin{array}{l}\text { Phase } 2 \\
\text { Word count }\end{array}$ & \\
\hline$\overline{\text { Anna }}$ & $\checkmark$ & 21,462 & $\checkmark$ & $\checkmark$ & $\checkmark$ & 15,294 & 36,756 \\
\hline Becky & $\checkmark$ & $2836^{*}$ & $\checkmark$ & $x$ & $\checkmark$ & 12,584 & 15,420 \\
\hline Cat & $\checkmark$ & 8043 & $x$ & $x$ & $\checkmark$ & 12,292 & 20,335 \\
\hline Donna & $\checkmark$ & 17,036 & $\checkmark$ & $\checkmark$ & $\checkmark$ & 17,792 & 34,828 \\
\hline Ellie & $\checkmark$ & 6680 & $\mathrm{n} / \mathrm{a}$ & $n / a$ & $\mathrm{n} / \mathrm{a}$ & $\mathrm{n} / \mathrm{a}$ & 6680 \\
\hline Fiona & $\checkmark$ & 4787 & $x$ & $\checkmark$ & $\checkmark$ & 7824 & 12,611 \\
\hline Gaby & $\checkmark$ & 9714 & $x$ & $\checkmark$ & $\checkmark$ & 11,494 & 21,208 \\
\hline Hayley & $\checkmark$ & 9116 & $\checkmark$ & $x$ & $\checkmark$ & 12,253 & 21,369 \\
\hline Imogen & $x$ & 6532 & $\checkmark$ & $x$ & $\checkmark$ & 10,237 & 16,769 \\
\hline Jess & $x$ & 9339 & $\checkmark$ & $x$ & $\checkmark$ & 11,130 & 20,469 \\
\hline Total & 8 & 95,545 & 6 & 4 & 9 & 110,900 & 206,445 \\
\hline
\end{tabular}

*Audio recording error 
analysis reported in this paper, an in-depth sociological analysis was undertaken on data relating to smoking during pregnancy; this was reported separately [46].

\section{Results}

A large body of data was collected. The life history interviews (phase 1) provided contextual information. Interviews two and three (phase 2) provided detailed accounts of health behaviours in pregnancy, including the three health behaviours reported here (smoking, drinking alcohol and infant feeding), alongside experience of sickness, being tired and diet. First, we present demographic details for the participants, alongside health behaviour in relation to maternal smoking and alcohol consumption and infant feeding experiences and intentions. Barriers and facilitators to meeting public health guidance in relation to the three core behaviours are then highlighted through the COM-B model.

\section{Demographics and self-reported health behaviours}

Demographic details for participants are reported in Table 3; in order to preserve anonymity only two indirect identifiers are used in this table. The median age of participants was 29 (range 24-34). Of the ten participants, nine already had children; one previous child was the most common $(n=5)$. Only one participant was educated to degree level. The majority of participants were recruited during the first trimester of pregnancy. In self-reported health behaviours from their previous and current pregnancies were inconsistent (see Table 3). For example, Anna and Cat described complete abstinence from alcohol at some points of the interview, but later made reference to occasional or regular low level alcohol consumption. Anna commented: "Like I don't go out, don't drink..." but later stated: "We now have the odd drink in the house but we don't go out." Similarly, during her first interview (with Dunla, who was pregnant at the time) Catt said she had been easily able to quit smoking, but in her third interview (with Dawn) noted that she was regularly smoking a small number of cigarettes per day. These presentations of self, highlight the moral and identity work that pregnant women undertake to present as responsible, despite researchers attempts to present themselves as non-judgemental.

Most participants reported their planned infant feeding strategy confidently; either to choose to try to initiate breastfeeding (often with a caveat that it would be acceptable to them if this was not successful) or to immediately feed the baby with infant formula. By contrast, Cat was highly conflicted about whether to attempt to initiate breastfeeding, describing factors for and against attempting to initiate throughout the data production phase, highlighting several issues to be explored further in the COM-B analysis:

"I have never liked, I don't, obviously, disagree with it, I agree with it but I, it's never, I've never, I couldn't do it, it's something that I don't agree with myself doing it, I just can't get the hang of it." (Cat)

\section{Barriers and facilitators to following public health guidance during pregnancy}

Participants reported a range of barriers and facilitators in attempting to follow public health guidance, and occasionally they reported contradictions; with barriers and facilitators focused around the same COM-B domain. It was common for the issues that participants described to impact on multiple areas of the COM-B model. The findings are presented below in relation to remaining smoke free, alcohol consumption and infant feeding, and summarised in Table 4.

\section{Remaining smoke free during pregnancy}

Guidance within the UK suggests that women should remain smoke free during pregnancy. The majority of the participants did not explicitly report that they had been told that the guidance was not to smoke, but this appeared to be because it was already a shared understanding between health professionals and pregnant women. Of the participants, two were current smokers, one was currently using an e-cigarette and three (including Becky who currently used an e-cigarette) had smoked during previous pregnancies. Of the remaining five participants, three reported they were non-smokers and smoking was not discussed with the final two participants (see Table 3). Both psychological and physical capability (see Table 1 for definitions of the COM-B model terms) was generally a facilitator to remaining abstinent, with knowledge of the potential harm to the foetus reported, and nausea and sickness a barrier to continual smoking:

"I was smoking I can't remember if it was 15 or 20 a day and then I fell pregnant with [daughter], and that was the whole scare factor again. But I did agree with what (the health professionals) were saying so I switched to (an e-cigarette) when I was pregnant with [daughter] and I've been on them for two and half years at least" (Becky, e-cig user, ex-smoker)

"But again that's the sickness thing at the beginning (of pregnancy) and I wasn't you know (smoking) comes hand in hand for me with drinking, or used to anyway..." (Hayley, abstinent, ex-smoker) 


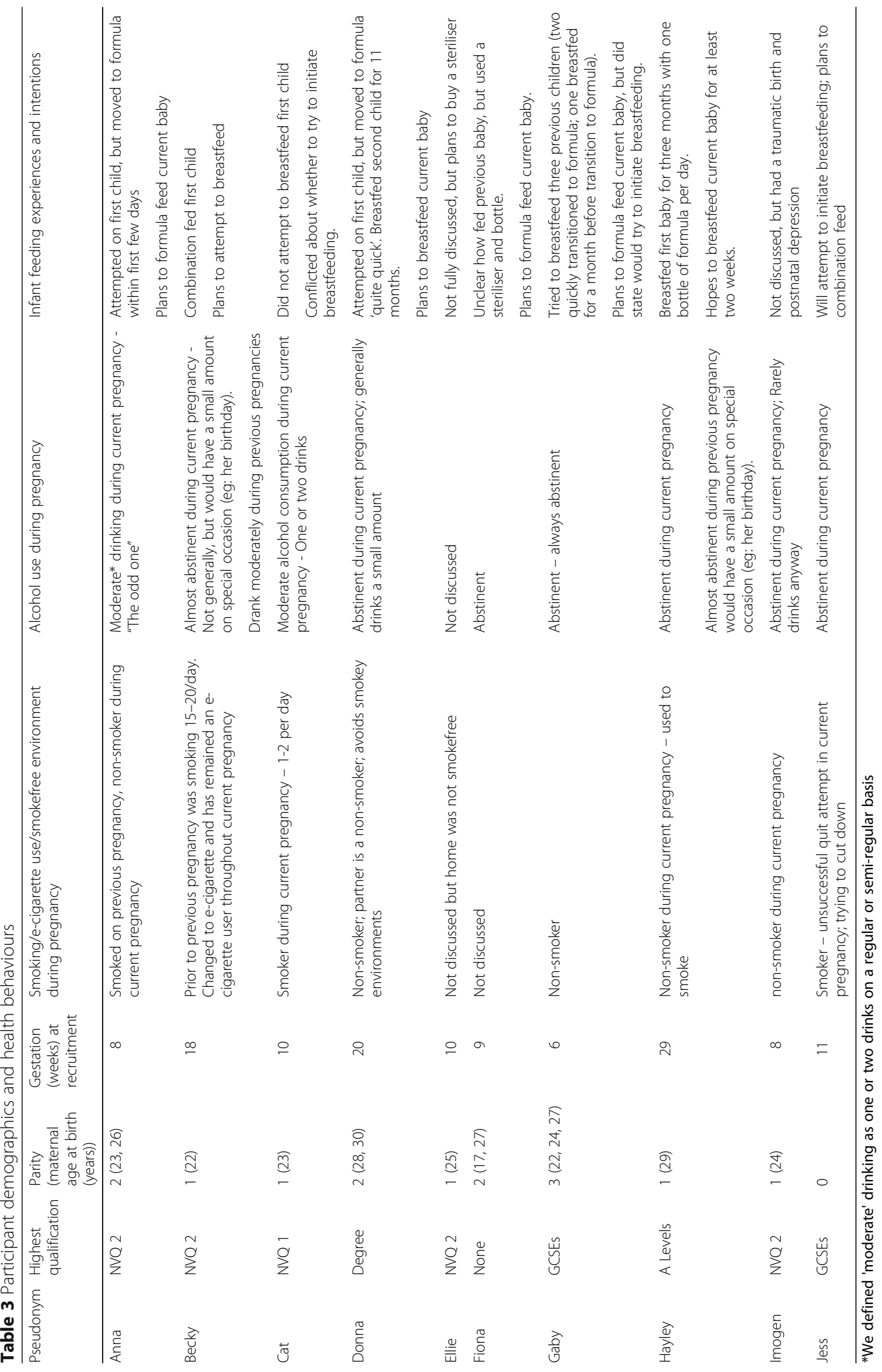


Table 4 Summary of themes arising during interviews corresponding to COM-B domains

\begin{tabular}{l} 
Drivers of behaviour: barriers $(-)$ and facilitators $(+)$ \\
\hline Remaining smokefree during pregnancy \\
Knowledge of potential harm $(+)$, including from health professionals $(+/-)$; high $(+)$ or low $(-)$ \\
Carbon Monoxide test readings; belief that harm from smoking is real $(+)$ or exaggerated $(-)$ \\
Pregnancy related nausea $(+)$ \\
Stress $(-)$ \\
Stigma related to smoking during pregnancy and pressure to stop smoking leads to hidden smoking in \\
the home and car $(-)$; smoking in pregnancy normalised $(-)$; strong family views that smoking is bad (+)
\end{tabular}

Nicotine addiction (-); cravings to smoke (-); feeling that e-cigarettes were unable to deliver sufficient nicotine to reduce cravings (-); life long non-smoker (+); association between drinking alcohol and smoking leads to reduced cravings when not drinking alcohol $(+)$

Remaining abstinent from alcohol during pregnancy

Knowledge of guidelines (+/-) including from health professionals (+/-); belief that any alcohol is dangerous $(+)$ or only heavy alcohol use is dangerous $(-)$; belief that alcohol is dangerous reduces appeal (-)

Pregnancy related nausea and tiredness reduce appeal (+); age and caring responsibilities for children make 'hangovers' unappealing $(+)$

Alcohol consumption in public is highly stigmatised (+/-); partners and family members encourage alcohol consumption in the home $(-)$;

Socialising largely takes place in premises serving alcohol and few non-alcoholic options (-); feelings of isolation from social group when not drinking alcohol (-)

Willpower sufficient to resist alcohol (+); alcohol associated with relaxation and pleasure, leading to strong desire to drink alcohol (-)

Breastfeed exclusively for six months

Knowledge of guidelines (+/-) including from health professionals (+/-); belief that breastmilk is superior to formula $(+/-)$; belief that exclusive breastfeeding is important $(+/-)$; belief that breastfeeding beyond the early days and weeks is important $(+/-)$

Breastfeeding $(+)$ or formula feeding $(-)$ positioned as the convenient or 'normal' choice by the mother, and those around her; Formula feeding culture $(-)$

Pressure to breastfeed from health professionals, family, friends and strangers in the antenatal and early post-natal period (-)

Understanding of how to physically breastfeed (including latch and positioning) (+/-); physical challenges, including soreness, latch and tongue-tie $(-)$; recovering from traumatic birth or $($-section $(-)$; support to overcome physical challenges from health professionals or others (+/-); hospitals have adequate/inadequate resources to support the initiation of breastfeeding $(+/-)$
COM-B domain

Capability psychological

Opportunity - social

Motivation - reflective

Capability - physical

Capability -

psychological

Opportunity - social

Opportunity -

environmental

Motivation - reflective

Motivation- automatic

Capability psychological

Opportunity - social

Motivation - reflective

Capability - physical

Opportunity - social

Motivation - reflective

Opportunity - social

Opportunity -

environmental

Opportunity - social

Opportunity -

environmental

Motivation- automatic

Opportunity - social

Capability psychological

Opportunity - social

Motivation - reflective

Capability psychological

Capability - physical

Opportunity - social

Motivation - reflective

Capability -

psychological

Opportunity - social

Capability psychological

Capability - physical

Opportunity - social 
Table 4 Summary of themes arising during interviews corresponding to COM-B domains (Continued)

\begin{tabular}{|c|c|}
\hline Drivers of behaviour: barriers $(-)$ and facilitators $(+)$ & COM-B domain \\
\hline & $\begin{array}{l}\text { Opportunity - } \\
\text { environmental }\end{array}$ \\
\hline \multirow{3}{*}{$\begin{array}{l}\text { Confidence in ability to breastfeed }(+/-) \text {; inability to see how much milk baby is taking }(-) \text {; belief in adequacy } \\
\text { of milk supply }(+/-) \text {; exposure to breastfeeding role models }(+) \text { or formula feeding role models }(-) \text {; } \\
\text { experience of formula feeding babies }(-)\end{array}$} & $\begin{array}{l}\text { Capability - } \\
\text { psychological }\end{array}$ \\
\hline & Capability - physical \\
\hline & Opportunity - social \\
\hline \multirow{4}{*}{$\begin{array}{l}\text { Belief that it is OK to breastfeed in public }(+) \text {; Confidence to breastfeed in public }(+/-) \text {; belief in ability to 'discreetly' } \\
\text { breastfeed in public }(+/-) \text {; knowledge of 'safe' places to breastfeed in public }(+) \text {; confidence-building support from } \\
\text { health professionals or others }(+)\end{array}$} & $\begin{array}{l}\text { Capability - } \\
\text { psychological }\end{array}$ \\
\hline & Capability - physical \\
\hline & Opportunity - social \\
\hline & $\begin{array}{l}\text { Opportunity - } \\
\text { environmental }\end{array}$ \\
\hline \multirow{3}{*}{$\begin{array}{l}\text { Partners and family encourage bottle feeding to 'help' with care }(-) \text { - expressing breastmilk for bottle feeding takes } \\
\text { additional time and maternal energy (-); mothers desire/ability to reject formula feeding }(+/-) \text {; belief breastfeeding } \\
\text { takes extra time }(-) \text { and lack of support for household chores and caring responsibilities }(-)\end{array}$} & Opportunity - social \\
\hline & Motivation - reflective \\
\hline & $\begin{array}{l}\text { Capability - } \\
\text { psychological }\end{array}$ \\
\hline \multirow{2}{*}{$\begin{array}{l}\text { Breasts identified as sexual (-); Desire to stop breastfeeding to 'get my body back' (-) and quickly return to non-maternal } \\
\text { activities/self identity (-) }\end{array}$} & Opportunity - social \\
\hline & Motivation - reflective \\
\hline
\end{tabular}

For some participants who smoked prior to pregnancy, stress reduced psychological capability to abstain from smoking:

"with (my most recent pregnancy)...towards the end, I had court with (my eldest daughter's) father so seeing as I couldn't drink, ok I did smoke five in a row because I was a bit stressed..." (Anna, abstinent; smoker during previous pregnancy)

There was little social opportunity for pregnant women to smoke. Participants who had smoked during pregnancy described how they would "never" smoke in public, and reported the judgements they had experienced from strangers when smoking or using an e-cigarette:

"I smoke my e-cig and some people...might look at me and like judge" (Becky, e-cig user, ex-smoker)

Alongside this, the majority of pregnant smokers highlighted pressure to abstain from members of their immediate social network, such as partners. This disapproval, however, resulted in the home (and for Jess, her car) becoming a safe place in which to smoke:

"When I was pregnant with [youngest daughter] and [eldest daughter] I did smoke with them but it was in my own house, I never walked around out and about with one, it's not the best look." (Anna, abstinent; smoker during previous pregnancy)
"My (car is my) bubble, I can cry, I can smoke, I can have a McDonalds in the car you know I can listen to music, I can do everything in the car." (Jess, smoker)

Those who had not smoked during a pregnancy reported a strong reflective motivation to not do so which affected their desire. By contrast, among women who smoked, the automatic motivation of addiction was prominent in discourses:

"Even when I am not pregnant I don't drink, I hate smoking, absolutely hate it. So yeah it's never affected me because...I don't miss it you know?" (Gaby, never smoked)

"No I smoked, I smoked and then I quit and then I, when I found out I did quit but then I started smoking again when I was pregnant and then I went onto those e-cig fags and then I stopped on that but now I am pregnant again I've started having a few fags again it's like I've got a craving for smoke or something, it's really weird" (Cat, smoker)

\section{Remaining abstinent from alcohol during pregnancy}

Guidance within the UK suggested that women should remain abstinent from alcohol during pregnancy, although this guidance was introduced around four months prior to this research beginning, and previous guidance advised women could drink a small amount of alcohol each week. Of the participants, six reported they were abstinent from alcohol 
during their current pregnancy (one of whom had experience of low levels of drinking alcohol in a previous pregnancy), three reported that they currently drank alcohol and alcohol was not discussed with one participant.

Unlike smoking during pregnancy, where psychological capability was enhanced through a high level of knowledge of guidelines, participants reported that they did not always know that complete abstinence was recommended, with one participant being confused about the change in guidance:

"...the alcohol thing changes all the time doesn't it? Like I think with (previous pregnancy) it was a nono and I think now you can have one, they don't recommend it obviously..." (Hayley, abstinent, drank alcohol during previous pregnancy)

Among women who were abstinent, knowledge of the potential negative impacts for babies in addition to the guideline were reported, and this impacted on reflective motivation:

"I have seen like things where babies have had problems because their mothers have been drinking alcohol and it's like it's not fair on the baby and it's how it makes me feel, when you have a drink you feel, sometimes you feel like whoa and I don't want to put a poor innocent baby through that really." (Fiona, abstinent)

As with smoking during pregnancy, nausea or extreme tiredness resulted in some participants losing their physical capability to drink alcohol. Social opportunities for drinking alcohol were focused in two areas. First, three partners and family members encouraged alcohol consumption, which some participants resisted, but others did not:

"I am sure, you can like (husband) has said oh I am sure it will be fine, just half a glass of wine." (Donna, abstinent)

"I did have one by the end of [baby son] you know I think it was around Christmas time I had a glass because [partner]s mum and my mum was like oh we had one with you, you're this far gone." (Hayley, abstinent, drank alcohol during previous pregnancy)

Second, participants described the centrality of alcohol to social occasions in their lives and how pregnancy disrupted this, either through removing their intention to drink alcohol, or by their consumption of alcohol being subjected to surveillance:
"I miss the social aspect of that obviously you can't drink when you're pregnant, you can't do a lot of things when you're pregnant (...) I miss going out because I didn't drink a lot before I was pregnant but now it's just like you know you can't and...." (Jess, abstinent)

"... in the end if my partner said anything I kind of just did the opposite just to you know prove a point, not, I wouldn't go to the length that I would think that my baby is being harmed but just to make that point of you know that it's nothing to do with you, this is my baby and my pregnancy. Because of Christmas we had I think it was champagne or wine or something and they were pouring it and my dad said: 'Oh no, (Becky) can't have any', and I said: 'Yes I can!' [laughs]. I poured my share and made the point of drinking it all because it's my baby and my pregnancy yeah. It irritates me so much when people say things like that because it's not, and it's men most of the time as well." (Becky, drinks alcohol occasionally)

This surveillance combined with a lack of alternatives to drinking alcohol resulted in participants feeling excluded from the night time economy. Accordingly, for those who did drink alcohol during pregnancy environmental opportunities were limited, and alcohol consumption was usually restricted to their home or the homes of friends.

Motivation to remain abstinent from alcohol was largely concentrated around reflective motivations. Among the abstinent participants, reflective motivation focused on the potential for drinking alcohol to harm the baby:

"You know it can't be that good (for the baby)" (Hayley, abstinent, drank alcohol during previous pregnancy)

By contrast, participants who had experience of drinking alcohol in pregnancy reported an alternative belief about harms to the baby, which focused only on 'heavy' use as dangerous for babies:

"I've had one or two drinks but some people they don't mind drinking quite a lot when they're pregnant but I don't agree with that, I don't mind having one or two, that can't hurt you at all but I wouldn't, I wouldn't go over the limit do you know what I mean? I don't agree with that but yeah I will have, I don't do it often like..." Cat, drinks alcohol regularly) 
Alongside acknowledgements of harm, the desire to consume alcohol was not always reduced, and in some participants this required will power:

"Oh I'd love one. (When we go on the hen night) It will kill me watching my mother with a bottle of wine, I'll be there with my glass of coke [laughs]". (Anna, drinks alcohol occasionally)

\section{Exclusive breastfeeding for six months}

Overall, participants knew that breastfeeding was the recommended food for babies, but they did not generally know why this was, or the full extent of the guidelines to exclusively breastfeed for the first six months and to continue until the infant was at least two years old. Hayley reported the most detailed knowledge, but her knowledge of duration was incorrect:

"Because of the goodness that can go through and strengthen the immune system (in the first 2 weeks) isn't it? I can't remember what they call it now... Especially when you get to six months and you don't have any nutrients from breast milk so technically you should introduce a bottle by then..." (Hayley, breastfed for three months previously; hopes to breastfeed)

Many participants who had previously been unsuccessful in breastfeeding their infants for as long as they had hoped reported reduced confidence (psychological capability), including in their physical ability to be able to breastfeed, and to breastfeed in public:

"I'm going to) bottle feed, yeah. I haven't got the confidence to breastfeed. I am unsure really (if I'd like to try if I had the confidence), I lack confidence in that sort of thing so I would need confidence to do it but if I had the confidence I probably would give it a go." (Fiona, attempted to breastfeed but early exclusive formula feeding previously; plans to formula feed)

"I'm not one of them people anyway even like when you're out and about and that, I'm just a shy person like that, I couldn't imagine myself doing it outside, I haven't got the guts to do it." (Cat, formula fed previously; unsure whether to attempt to breastfeed)

Physical capability was highlighted as a major barrier to breastfeeding babies, including lack of understanding of how to breastfeed, tongue ties and traumatic births:

"For the first two and half weeks you get, your boobs are so sore and you're kind of just practising how to do it and they're biting the wrong bits and sucking the wrong bit and then you get like bad blisters like all the way round and it's so painful." (Becky, combination fed previously; hopes to breastfeed)

However, those who had breastfed beyond the early weeks noted that breastfeeding became the physically easy option:

"you'd be amazed what you can kind of get done [laughs] when you're feeding a baby. Whereas actually when you're feeding a baby with a bottle, the kind of, it's quite difficult you can't really do much and I found that I was quite tied to a sofa" (Donna, formula fed first child, exclusively breastfed second child, plans to breastfeed)

In relation to social opportunities, social norms could be a barrier and facilitator to breastfeeding, depending on whether they were focused on formula- or breast-feeding. For one participant who had previously formula fed, positive exposure to breastfeeding was a factor in her considering breastfeeding her forthcoming baby:

"my brother's girlfriend now with my niece, she is breastfeeding and she said it's you know it's so easy, you get such a closer bond as well so I am really thinking about it this time around." (Cat, formula fed previously; unsure whether to attempt to breastfeed)

Whilst social norms generally appeared relatively unobtrusive in participants' accounts of initiating breastfeeding, when participants described infant feeding in public, it was clear that social opportunity played a major roll:

"everyone has got an opinion on (breastfeeding in public) and it's quite, quite interesting listening to people and they're like: 'I'll do it anywhere'. I'm not that sort of person, I wouldn't just do it anywhere, I'd feed them you know I don't know if we were in a café or if we were in a restaurant or we'd gone to I don't know in a park on a bench somewhere. So yeah I think I'd still be mindful of other people because I

understand that some people don't want to, they don't want to see it or they think it's not right, it should be something that's done at home..." (Donna, formula fed first child, exclusively breastfed second child, plans to breastfeed)

Environmental opportunities were almost always highlighted as a barrier to breastfeeding, with inadequate support to learn how to physically breastfeed, and health service promotion of formula feeding: 
"And this one I am just thinking I am just going to do straight to the bottle because I was in hospital for an extra two nights trying to breastfeed [baby son] and not one of them picked up on the tongue tie..." (Gaby, formula fed two previous children, breastfed third child for one month; plans to formula feed)

Alongside this, 'help' with feeding the baby was offered by partners and other family members:

"I know (my husband) has got this system in place about feeding, how he will have the graveyard shift and I'll have the rest of the day so I need to, in fact if it's going to be breast obviously I've got to think about expressing and stuff like that. Like I said because he is going away (for work for a few months) you know the plan is at the moment him going away, I don't have to worry about which it is." (Jess, first child, plans to attempt to breastfeed)

Participants reported mostly reflective motivations in their choice of infant feeding method. These focused on breastfeeding as "worth it" (Becky), or statements about the comparability of formula and breast milk:

"I was bottle fed and there is nothing wrong with me so that's what is in my head, I don't think it's wrong either way." (Hayley, breastfed for three months previously; hopes to breastfeed)

Alongside this, a major reflective motivation for stopping breastfeeding before the 24 month guideline was to "(get) my body back" (Donna; Gaby):

"...although sometimes now, (my daughter) is still tugging at my top and I'm like, (daughter), no, get off (laughs). I was like no, it got to the point I thought I need my body back now, this is it now, you can have your milk, you can have a bottle." (Donna, formula fed first child, exclusively breastfed second child, plans to breastfeed)

\section{Absent voices}

It is interesting to note that Imogen did not appear in the mapping of the data to the COM-B model, and this is because the health behaviour that mattered most to Imogen was maintaining a healthy weight and diet throughout her pregnancy, which was described at length during interviews. It may be that Imogen's assertion that she does not drink or smoke made the space for this concern about weight and diet, that was much less present in the other interviewee's accounts.

\section{Discussion}

Among the ten participants from deprived areas involved in this research, none met the public health guidelines to be abstinent from alcohol [4] and tobacco [3] during pregnancy and to breastfeed their babies to 24 months and beyond [7, 8]. Overall, our findings mirror much of the previous research, often undertaken with more affluent women, as will be explored in more detail below. Knowledge about remaining abstinent from smoking was generally high, but lower in relation to remaining abstinent from alcohol and even lower in relation to breastfeeding beyond six months. Research into knowledge of alcohol guidelines in Australia has been inconsistent, with some studies highlighting mixed-messages and confusion [47] whilst others report high levels of knowledge, but lack of compliance with guidelines [6]. Previous research on knowledge of breastfeeding guidance from the UK Infant Feeding Survey reports that there is a strong social-class dimension to knowledge of the benefits of breastfeeding [48].

Furthermore, confidence to be able to breastfeed their babies, especially in public or in front of other people, was low in the majority of participants, further affecting psychological capability. Physical capability was generally high in relation to abstaining from alcohol and cigarettes, although it was a significant barrier to breastfeeding babies, with a range of factors relating to pain, latch and tongue ties. Confidence and physical capability to breastfeed - particularly when in a public setting - have been widely reported as barriers to breastfeeding in women from deprived [63] and more affluent backgrounds [49]. However, poverty presents additional barriers to physical and psychological capability [50], and should not be underestimated in the design of new interventions.

In relation to social opportunity, both smoking in public and drinking alcohol in public was viewed as unacceptable. Whilst on the face of it, this may seem as though it is a positive factor, women reported feeling stigmatised, judged and isolated. This finding mirrors previously recognised stigma against smokers in general [51], female smokers more specifically [52] and pregnant smokers as those breaching public health and feminine ideals [53]. Alcohol use generally is less stigmatised than smoking in the UK, and drinking small amounts during pregnancy is viewed as acceptable, whilst heavy drinking is demonised [54]. That said, concerns have been raised that interventions at the point of purchase may further stigmatise pregnant women, whilst having little effect on incidence of harm to babies [55]. We found that lack of social opportunity did not stop participants from smoking and drinking alcohol, as environmental opportunities in the shape of homes and other private spaces provided a safe place to engage in these behaviours. 
One area of differences was that partners attempted to dissuade smoking during pregnancy, but facilitated and sometimes encouraged alcohol use during pregnancy. Research from the Netherlands also highlighted partners, the majority of whom had a university degree, encouraged light drinking in their pregnant partners [56]. Interestingly, the major social opportunity barrier that women reported in relation to breastfeeding was the need to breastfeed in public, which they feared would attract comments, looks and judgement which, again made them feel self-conscious and affected their confidence to breastfeed their babies at all. This has been widely reported in research with mothers, both in deprived [63] and affluent [49] areas of the UK.

Alongside this, environmental opportunities to negate physical capability challenges associated with breastfeeding were often reported to be inadequate. Midwives were often described as providing pressure in the antenatal period, but a lack of meaningful support in the immediate postnatal period, as has been reported in a repeat interview study with a mixture of women from deprived and affluent backgrounds in the UK [57]. Moreover, partners often offered help in the form of formula feeding babies, undermining exclusive breastfeeding, and in contrast to another study, which recruited male partners of women who breastfed exclusively for six months. These fathers used a range of other strategies to support infant feeding [58].

The final factor, motivation, was involved in all three behaviours. In relation to smoking, those who smoked stressed their automatic motivation through addiction and in some cases the beneficial effect that pregnancy-induced-nausea had on their ability to quit, as has been reported among indigenous women, a population where one in two women smoke [59]. By contrast, those who were abstinent highlighted their reflective motivation in the form of strong views that smoking was, and sometimes smokers were, bad, resonating with previous accounts of class-based othering [51].

In contrast, motivation to remain abstinent from alcohol was largely related to perceived ill effects for the baby, and among those who drank alcohol, a distinction was made between 'safe' and harmful levels of alcohol which was broadly in line with the previous UK guidance. This may be due to the relatively short period of time between the introduction of the new guidance and the data production period. Other explanations include a lack of discussion from midwives if women are perceived not to drink alcohol [60] or miscommunication [61].

Motivation in relation to breastfeeding was described less, although those with low confidence in their ability to breastfeed repeated their doubts in their ability to successfully nourish their babies, which is frequently reported among women who transition to formula feeding earlier than they had planned [48]. Alongside this, women who breastfed their babies reported getting to a point (from 1 to 11 months) where they wanted to stop breastfeeding to "get my body back", articulating both the hyper-sexualisation of the breast in Western societies [62], and the greater burden of caring for infants which can fall to breastfeeding mothers if partners are not supportive [58].

In terms of further intervention development, we have highlighted partners, the public and health service staff as potential intervention participants and/or delivery partners to help facilitate these three behaviours. However, as the above comparison of the three behaviours in relation to the COM-B framework show, a range of approaches is necessary to facilitate a change in maternal behaviour. Accordingly, multi-behaviour interventions delivered through maternity services may not be appropriate for women during pregnancy [13]. Moreover, social and environmental opportunities should be considered, in relation to all three behaviours.

In relation to smoking and alcohol use in pregnancy in particular, we need to move away from an approach of individualised blaming [9], and consider how we can engage social networks in positive and supportive behaviours. In relation to breastfeeding, barriers to breastfeeding in public have been previously highlighted [63]. This is despite the Equality Act 2010 providing protection for women to breastfeed in public space. It is clear that some members of the public find viewing breastfeeding disgusting or distasteful [64], and interventions are urgently needed to normalise public breastfeeding, to provide a safe space for women who do wish to breastfeed.

\section{Strengths and limitations}

This study aimed to gain a detailed understanding of health behaviours during pregnancy from the subjective accounts of pregnant women living in deprived areas of the UK and claiming means tested benefits. Consequently we worked with a small sample of ten women, who were interviewed three times, creating a nuanced qualitative data set in excess of 200,000 words. That said, our sample was not diverse in terms of ethnicity, and it is likely that the experiences of low income Black and minority ethnic women, framed by an additional lens of race and racism, would vary from our findings [65]. Furthermore, nine of the ten interviewees were already mothers, and their experiences may vary to women who are primigravida. Accordingly, a small sample of white women from a narrowly defined geographical area limits opportunities for generalisation. Additionally, we did not collect data on all three health behaviours from every 
participant and no details were requested in relation to whether pregnancies were low- or high-risk or whether obstetric diseases had occurred, although none were disclosed. A further limitation of our approach was a lack of participant validation of analysis.

Nevertheless, the research aims did not align with the quantitative sampling frame required to engender generalisability, and the positioning of participants as experts, necessarily produced data that emphasised participants, rather than researchers, salient areas of focus. Despite the lack of opportunity for participant validation of analysis, we undertook further stakeholder consultation with mothers and health professionals, which provided both a confirmation of the key themes reported, and additional insights into the next steps for this research.

\section{Conclusions}

This paper highlighted a range of barriers to remaining abstinent from smoking and alcohol during pregnancy, and for breastfeeding among women from deprived areas of the UK. Mapping to the COM-B model illustrated the variation in barriers to achieving each behaviour. It is therefore unsurprising that multi-behaviour interventions often fail to achieve their multiple aims. Overall, the core influences in our three target behaviours appeared to be knowledge, confidence, partner support, and expert support to overcome physical challenges associated with addiction (smoking) and learning new techniques (breastfeeding). Alongside this, smoking, drinking alcohol (or even being present in places serving alcohol), and breastfeeding led to public condemnation of women, which may position them as failed maternal subjects. The need to retain bodily autonomy was also a barrier to breastfeeding.

Within the COM-B model, existing behaviours affect all three elements (Capability, Opportunity and Motivation); this should be considered within intervention design [24]. Importantly, this study has highlighted that when designing new interventions targeting women from deprived populations and our three target behaviours, it is important to co-produce the intervention with them in order to recognise the stigma and challenges to a good maternal-identity inherent within contemporary UK society. This involvement of women should not be a tokenistic exercise but one which is carefully designed to enable women to communicate their own subjective experiences and understandings of pregnancy and motherhood. In gaining an insight into the meaning making of women it is hoped that moves can be made to adopt interventions which are theoretically robust from the bottom up [66] which can potentially improve the health and wellbeing of mothers and their children.

\section{Additional file}

Additional file 1: COREQ (COnsolidated criteria for REporting Qualitative research) Checklist (PDF $486 \mathrm{~kb}$ )

Abbreviation

COM-B model: Capability, Opportunity, Motivation-Behaviour model

\section{Acknowledgements}

We would like to thank all of the participants who provided their time to this study, and also disclosed highly sensitive information. We were able to learn a great deal about the application of the COM-B model from the ABACus study, and in particular Dr. Stephanie Smits, Dr. Grace McCutchan and Dr. Kate Brain who kindly shared their analysis workbook.

\section{Availability of data and material}

in line with guidance on preparing data for secondary analysis, this expansive qualitative dataset comprising verbatim transcripts will not be made available [67].

\section{Funding}

This research was funded by the Wellcome Trust (Reference Number: $105613 / Z / 14 / Z)$. The funding body played no role in the design of the study and collection, analysis, and interpretation of data and in writing this manuscript.

\section{Authors' contributions}

AG was the study PI, and oversaw the research on a day-to-day basis. AG and DM designed the research and secured funding for the study. DG was the research assistant and produced some data and contributed to initial analysis MM was DG's maternity cover, and produced the majority of the data and undertook initial coding. DM conducted a second stage interview with one participant and provided expertise in the production of visual data. AGoversaw initial coding, second coded all transcripts for content relevant to this manuscript and undertook mapping to the behaviour change wheel. All authors read and approved the final manuscript.

\section{Authors' information}

Dr. Aimee Grant (GrantA2@cardiff.ac.uk); Dr. Melanie Morgan (MorganML1@cardiff.ac.uk); Dr. Dunla Gallagher (D.Gallagher@qub.ac.uk) and Dr. Dawn Mannay (MannayDl@cardiff.ac.uk).

Ethics approval and consent to participate

This study was awarded ethical approval by Cardiff University School of Medicine ethics committee. All participants provided written consent to participate in the study, and for their interviews to be audio recorded.

\section{Consent for publication}

all participants were given the option of allowing verbatim quotations to be used in publications. All participants provided this consent in writing.

\section{Competing interests}

The authors declare that they have no competing interests.

\section{Publisher's Note}

Springer Nature remains neutral with regard to jurisdictional claims in published maps and institutional affiliations.

\section{Author details}

${ }^{1}$ Centre for Trials Research, Cardiff University Neuadd Meirionnydd, Heath Park, Cardiff CF14 4YS, UK, Wales. ${ }^{2}$ School of Social Sciences, Cardiff University, Glamorgan Building, King Edward VII Avenue, Cardiff CF10 3WT, UK. ${ }^{3}$ Centre for Public Health, Institute of Clinical Sciences, Queens University Belfast, Belfast, UK, Ireland. 


\section{Received: 4 November 2017 Accepted: 17 December 2018} Published online: 12 February 2019

\section{References}

1. Neuman $\AA$, Hohmann C, Orsini N, Pershagen G, Eller E, Kjaer HF, et al. Maternal smoking in pregnancy and asthma in preschool children: a pooled analysis of eight birth cohorts. Am J Respir Crit Care Med. 2012;186:1037-43.

2. Passaro KT, Little RE, Savitz DA, Noss J, Team AS. The effect of maternal drinking before conception and in early pregnancy on infant birthweight. Epidemiology. 1996:377-83.

3. National Institute for Health and Care Excellence. Smoking: stopping in pregnancy and after childbirth | Guidance and guidelines | NICE [Internet]. NICE; 2010. Available from: https://www.nice.org.uk/guidance/PH26

4. Department of Health. UK Chief Medical Officers' Alcohol Guidelines Review [Internet]. 2016. Available from: https://www.gov.uk/government/uploads/ system/uploads/attachment_data/file/489795/summary.pdf

5. Britton A. Alcohol consumption for women trying to conceive. BMJ [Internet]. 2016 [cited 2017 22];i4540. Available from: http://www.bmj. com/lookup/doi/10.1136/bmj.i4540

6. Holland K, McCallum K, Walton A. 'I'm not clear on what the risk is': women's reflexive negotiations of uncertainty about alcohol during pregnancy. Health. Risk Soc. [internet]. Taylor \& Francis; 2016;18:38-58. Available from: https://doi.org/10.1080/13698575.2016.1166186.

7. World Health Organization. Breastfeeding [Internet]. WHO. World Health Organization; 2017 [cited 2017 Feb 7]. Available from: http://www.who. int/topics/breastfeeding/en/

8. NICE. Maternal and Child Nutrition [PH 11] [Internet]. 2008. Available from: https://www.nice.org.uk/guidance/PH11

9. Lupton D. 'Precious cargo': foetal subjects, risk and reproductive citizenship. Crit Public Health 2012;22:329-340.

10. Flemming K, Graham H, Heirs M, Fox D, Sowden A. Smoking in pregnancy: a systematic review of qualitative research of women who commence pregnancy as smokers. J Adv Nurs. 2013;69:1023-36.

11. Gamble J, Grant J, Tsourtos G. Missed opportunities: A qualitative exploration of the experiences of smoking cessation interventions among socially disadvantaged pregnant women. Women and Birth [Internet]. 2015 [cited 2017 Jul 31];28:8-15. Available from: http:// linkinghub.elsevier.com/retrieve/pii/S1871519214001012

12. Antin TMJ, Annechino R, Hunt G, Lipperman-Kreda S, Young M. The gendered experience of smoking stigma: implications for tobacco control. Crit. Public Health [Internet]. Taylor \& Francis; 2016;1596:1-12. Available from: https://www.tandfonline.com/doi/full/10.1080/09581596. 2016.1249825

13. Sanders J, Hunter B, Warren L. A wall of information? Exploring the public health component of maternity care in England. Midwifery [Internet]. 2016 [cited 2017 Sep 22];34:253-60. Available from: https://www.sciencedirect. com/science/article/pii/S026661381500282X.

14. Chamberlain C, O'Mara-Eves A, Porter J, Coleman T, Perlen S, Thomas J, et al. Psychosocial interventions for supporting women to stop smoking in pregnancy. Cochrane Database Syst Rev. 2017;2

15. Robling M, Bekkers M-J, Bell K, Butler CC, Cannings-John R, Channon S, et al Effectiveness of a nurse-led intensive home-visitation programme for firsttime teenage mothers (building blocks): a pragmatic randomised controlled trial. Lancet Elsevier; 2016;387:146-155.

16. Tappin D, Bauld L, Purves D, Boyd K, Sinclair L, MacAskill S, et al Financial incentives for smoking cessation in pregnancy: randomised controlled trial. BMJ [internet]. 2015;350:h134. Available from: https://www.bmj.com/ content/350/bmj.h134.

17. Boyd KA, Briggs AH, Bauld L, Sinclair L, Tappin D. Are financial incentives cost-effective to support smoking cessation during pregnancy? Addiction [Internet]. 2016 [cited 2017 Sep 22];111:360-70. Available from: http://doi. wiley.com/10.mcn.12703/add.13160

18. Thomson G, Dykes F, Hurley MA, Hoddinott P. Incentives as connectors: insights into a breastfeeding incentive intervention in a disadvantaged area of north-West England. BMC Pregnancy Childbirth. 2012;12.

19. Giles EL, Sniehotta FF, Mc Coll E, Adams J. Acceptability of financial incentives for health behaviour change to public health policymakers: a qualitative study. BMC Public Health [Internet]. BioMed Central; 2016 [cited 2017 22];16:989. Available from: http://bmcpublichealth.biomedcentral.com/ articles/10.1186/s12889-016-3646-0
20. Whelan B, Thomas KJ, Cleemput P Van, Whitford H, Strong M, Renfrew MJ, et al Healthcare providers' views on the acceptability of financial incentives for breastfeeding: a qualitative study. BMC Pregnancy Childbirth [Internet]. BioMed Central; 2014 [cited 2017 22];14:355. Available from: http://bmcpregnancychildbirth.biomedcentral.com/ articles/10.1186/1471-2393-14-355

21. Giles EL, Holmes M, McColl E, Sniehotta FF, Adams JM. Acceptability of financial incentives for breastfeeding: thematic analysis of readers' comments to UK online news reports. BMC Pregnancy Childbirth. 2015;15.

22. Whitehead $M$, Dahlgren $G$. What can be done about inequalities in health Lancet. 1991:338:1059-63.

23. World Health Organization. Global strategy for infant and young child feeding [internet]. Geneva: World Health Organization; 2015. Available from: http://www.who.int/nutrition/topics/global_strategy_iycf/en/

24. Michie S, van Stralen M, West R. The behaviour change wheel: a new method for characterising and designing behaviour change interventions. Implement Sci. 2011;6:42

25. Lee A, Belski R, Radcliffe J, Newton M. What do pregnant women know about the healthy eating guidelines for pregnancy? A web-based questionnaire. Matern Child Health J. 2016;20:2179-88.

26. Russell CG, Taki S, Azadi L, Campbell KJ, Laws R, Elliott R, et al A qualitative study of the infant feeding beliefs and behaviours of mothers with low educational attainment. BMC Pediatr. [Internet]. 2016;16:69. Available from: https://doi.org/10.1186/s12887-016-0601-2

27. Gould GS. Exploring the barriers and enablers to smoking cessation in pregnant aboriginal and Torres Strait islander women with the behavior change wheel. Australas Epidemiol. 2014;21:31.

28. Al Khamis S, Asimakopoulou K, Newton JT, Daly B. Oral health knowledge, attitudes, and perceptions of pregnant Kuwaiti women: a qualitative study. JDR Clin Transl Res. 2016;1:211-7 Available from: http://jct.sagepub.com/ content/1/3/211.abstract

29. Phillips, R., Copeland, L., Grant, A., Gobat, N., Stanton, H, Brown, A., Paranjothy, S. (2018) Development of a novel motivational interviewing (MI) informed peer-support intervention to support mothers to breastfeed for longer. BMC Pregnancy and Childbirth. https://doi.org/10.1186/s12884-0181725-1.

30. Copeland, L, Merrett, L, Grant, A. Gobat, N, Tedstone, S, McQuire, C, Playle, S, Channon, S, Sanders, J, Phillips, R, Hunter, B, Brown, A, Fitzsimmons, D, Robling, M., and Paranjothy, S. (2018) The feasibility and acceptability of providing a novel breastfeeding peer-support intervention informed by Motivational Interviewing. Maternal and Child Nutrition. https://doi.org/10. 1111/mcn.12703.

31. Jolly M. Better beginnings improving health for pregnancy. 2017. Available from: http://www.uhs.nhs.uk/Media/SUHTInternet/Services/Maternity/Betterbeginnings-Improving-health-for-pregnancy.pdf

32. Tong A, Sainsbury P, Craig J. Consolidated criteria for reporting qualitative research (COREQ): a 32-item checklist for interviews and focus groups. Int. J. Qual. Heal. Care [Internet]. II A structured review and evaluation of studies, Qualitative research in health care; 2007 [cited 2017 15];19:349-57. Available from: https://academic.oup.com/intqhc/article-lookup/doi/10.1093/intqhc/ mzm042

33. Preston-Shoot M. Whose lives and whose learning? Whose narratives and whose writing? Taking the next research and literature steps with experts by experience. Evid Policy. 2007;3:343-59.

34. Mitchell C. Doing visual research. London: Sage; 2011.

35. Mannay D, Morgan M, Marzella R, Gallagher D, Mason S, Mannay J, et al. Negotiating closed doors and constraining deadlines: the potential of visual ethnography to effectually explore spaces of motherhood and mothering. J. Contemp. Ethnogr. 2017; Online Fir.

36. Grant A. Doing EXCELLENT social research with documents: practical examples and guidance for qualitative researchers. Abingdon: Routledge; 2019.

37. Stats Wales. Welsh index of multiple deprivation (WIMD) 2015 [Internet] 2015 [cited 2017 Dec 4]. Available from: http://gov.wales/statistics-andresearch/welsh-index-multiple-deprivation/?lang=en

38. Coffey A. The ethnographic self: fieldwork and the representation of identity. London: Sage; 1999.

39. Wilkinson C. 'Babe, I like your lipstick': rethinking researcher personality and appearance. Child. Geogr. [Internet]. Taylor \& Francis; 2016;14:115-23. Available from: http//www.tandfonline.com/doi/full/10.1080/14733285.2015. 1039370 
40. Adriansen HK. Timeline interviews: a tool for conducting life history research. Qual Stud. 2012;3:40-55.

41. Gabb J, Fink J. Telling moments and everyday experience: multiple methods research on couple relationships and personal lives. In: Sociology, vol. 49. UK: London, England: SAGE PublicationsSage; 2015. p. 970-87.

42. Mannay D, Staples E, Edwards V. Visual methodologies, sand and psychoanalysis: employing creative participatory techniques to explore the educational experiences of mature students and children in care. Vis. Stud. 2017; In press.

43. Michie $S$, Atkins $L$, West $R$. The behaviour change wheel: a guide to designing interventions. Sutton: Silverback Publishing; 2014

44. Barbour RS. Checklists for improving rigour in qualitative research: a case of the tail wagging the dog? BMJ [Internet]. 2001;322:1115 LP-1117. Available from: http://www.bmj.com/content/322/7294/1115.abstract

45. Malterud K, Siersma VD, Guassora AD. Sample Size in Qualitative Interview Studies: Guided by Information Power. Qual. Health Res. [Internet]. 2016;26: 1753-60. Available from: http://qhr.sagepub.com/content/26/13/1753. abstract

46. Grant A, Morgan M, Gallagher D, Mannay D. Smoking during pregnancy, stigma and secrets: Visual methods exploration in the UK. Women and Birth [Internet]. Elsevier; 2018 [cited 2018 Dec 13]; Available from: https://www. sciencedirect.com/science/article/pii/S1871519218306085?via\%3Dihub

47. Anderson AE, Hure AJ, Kay-Lambkin FJ, Loxton DJ. Women's perceptions of information about alcohol use during pregnancy: a qualitative study. BMC Public Health. 2014;14.

48. Health \& Social Care Information Centre. Infant feeding survey - UK, 2010. 2012 [cited 2017 Oct 7]. Available from: http://www.hscic.gov.uk/catalogue/ PUB08694

49. Boyer K. Affect, corporeality and the limits of belonging: breastfeeding in public in the contemporary UK. Health Place. 2012;18:552-60.

50. Groleau D, Rodriguez C. Breastfeeding and Poverty: negotiating cultural change and symbolic capital of motherhood in Quebec, Canada. In: Dykes F, Hall-Moran V, editors. Infant Young Child Feed. London: Wiley; 2009. p. 232.

51. Graham H. Smoking, stigma and social class. J Soc Policy. 2012;41:83-99.

52. Alexander S, Frohlich KL, Poland B, Haines RJ, Maule C. I'm a young student, I'm a girl ... and for some reason they are hard on me for smoking: The role of gender and social context for smoking behaviour. Crit Public Health [Internet] 2010;20:323-38. Available from: http://www.tandfonline.com/doi/ abs/10.1080/09581590903410197

53. Wigginton B, Lee C. A story of stigma: Australian women's accounts of smoking during pregnancy. Crit. Public Health. 2013;23:466-81. Available from: http://www.tandfonline.com/doi/abs/10.1080/09581596.2012.753408

54. Lowe P, Lee E, Yardley L. Under the Influence? The Construction of Foetal Alcohol Syndrome in UK Newspapers. Sociol. Res. ONLINE. 1 OLIVERS YARD, 55 CITY ROAD, LONDON EC1Y 1SP, ENGLAND: SAGE PUBLICATIONS LTD; 2010;15.

55. Bell E, Zizzo N, Racine E. Caution Warning labels about alcohol and pregnancy: unintended consequences and questionable effectiveness. Am J Bioeth. 2015;15:18-20.

56. van der Wulp NY, Hoving C, de Vries H. A qualitative investigation of alcohol use advice during pregnancy: Experiences of Dutch midwives, pregnant women and their partners. Midwifery [Internet]. Churchill Livingstone; 2013 [cited 2018 Apr 9];29:e89-98. Available from: https://www. sciencedirect.com/science/article/pii/S0266613812002215

57. Hoddinott $P$, Craig LCA, Britten J, Mc Innes RM. A serial qualitative interview study of infant feeding experiences: idealism meets realism. BMJ Open [Internet]. British Medical Journal Publishing Group; 2012 [cited 2017 Feb 27];2:e000504. Available from: https://bmjopen.bmj.com/content/2/2/ e000504.

58. Demontigny F, Gervais C, Lariviere-Bastien D, St-Arneault K. The role of fathers during breastfeeding. Midwifery. 2018;58:6-12.

59. Gould GS, Bovill M, Clarke MJ, Gruppetta M, Cadet-James Y, Bonevski B. Chronological narratives from smoking initiation through to pregnancy of indigenous Australian women: a qualitative study. Midwifery. 2017:52:27-33.

60. Jones SC, Telenta J, Shorten A, Johnson K. Midwives and pregnant women talk about alcohol: what advice do we give and what do they receive? Midwifery. 2011;27:489-96.

61. Crawford-Williams F, Steen M, Esterman A, Fielder A, Mikocka-Walus A. "My midwife said that having a glass of red wine was actually better for the baby $\{$ " $\}$ : a focus group study of women and their partner's knowledge and experiences relating to alcohol consumption in pregnancy. BMC Pregnancy Childbirth. 2015;15.

62. Yalom M. A history of the breast. New York: Ballantine; 1997.

63. Grant A, Mannay D, Marzella R. "People try and police your behaviour": the impact of surveillance on mothers' and grandmothers' perceptions and experiences of infant feeding. Fam. Relationships Soc. 2017;Online fir:DOI: https://doi.org/10.1332/204674317X14888886530223.

64. Grant A. "I... don't want to see you flashing your bits around": exhibitionism, othering and good motherhood in perceptions of public breastfeeding. Geoforum [internet]. Elsevier Ltd; 2016;71:52-61. Available from: https://doi. org/10.1016/j.geoforum.2016.03.004

65. Ware $J$, Webb L, Levy M. Barriers to breastfeeding in the African American population of Shelby County, Tennessee. 2014;The Official Journal of the Academy of Breastfeedi.

66. Craig P, Dieppe P, Macintyre S, Michie S, Nazareth I, Petticrew M. Developing and evaluating complex interventions: the new Medical Research Council guidance. Br Med J. 2008;337.

67. Hrynaszkiewicz I, Norton ML, Vickers AJ, Altman DG. Preparing raw clinical data for publication: guidance for journal editors, authors, and peer reviewers. Trials [Internet]. 2010 [cited 2017 15];11:9. Available from: http:// trialsjournal.biomedcentral.com/articles/10.1186/1745-6215-11-9

\section{Ready to submit your research? Choose BMC and benefit from:}

- fast, convenient online submission

- thorough peer review by experienced researchers in your field

- rapid publication on acceptance

- support for research data, including large and complex data types

- gold Open Access which fosters wider collaboration and increased citations

- maximum visibility for your research: over $100 \mathrm{M}$ website views per year

At BMC, research is always in progress.

Learn more biomedcentral.com/submissions 